\title{
The relative risk of aortic aneurysm in patients with giant cell arteritis compared with the general population of the UK
}

\author{
Joanna C Robson, ${ }^{1}$ Amit Kiran, ${ }^{1}$ Joe Maskell, ${ }^{2}$ Andrew Hutchings, ${ }^{3}$ Nigel Arden, ${ }^{1}$ \\ Bhaskar Dasgupta, ${ }^{4}$ William Hamilton, ${ }^{5}$ Akan Emin, ${ }^{6}$ David Culliford, ${ }^{2}$ \\ Raashid A Luqmani ${ }^{1}$
}

\begin{abstract}
Handling editor Tore K Kvien
- Additional material is published online only. To view please visit the journal online (http://dx.doi.org/10.1136/ annrheumdis-2013-204113)

${ }^{1}$ Nuffield Department of Orthopaedics, Rheumatology and Musculoskeletal Science, University of Oxford, Nuffield Orthopaedic Centre, Oxford, UK

${ }^{2}$ Faculty of Medicine, University of Southampton, Southampton General Hospital,

Southampton, UK

${ }^{3}$ Department of Health Services Research and Policy, London School of Hygiene and Tropical Medicine Room, London, UK ${ }^{4}$ Department of Rheumatology, Southend University Hospital NHS Trust, Westcliff-on-sea, UK ${ }^{5}$ Primary care diagnostics, University of Exeter Medical School, Exeter, UK

${ }^{6}$ Clinical Effectiveness Unit, The Royal College of Surgeons of England, London, UK
\end{abstract}

\section{Correspondence to} Dr Joanna C Robson, Nuffield Department of Orthopaedics, Rheumatology and

Musculoskeletal Science,

University of Oxford, Nuffield Orthopaedic Centre, Windmill Road, Oxford OX3 7HE, UK; joanna.robson@ndorms.ox.ac. uk

Received 14 June 2013 Revised 9 August 2013 Accepted 20 September 2013 Published Online First 4 October 2013

\section{CrossMark}

To cite: Robson JC,

Kiran A, Maskell J, et al.

Ann Rheum Dis

2015:74:129-135.

\section{ABSTRACT}

Objectives To evaluate the risk of aortic aneurysm in patients with giant cell arteritis (GCA) compared with age-, gender- and location-matched controls.

Methods A UK General Practice Research Database (GPRD) parallel cohort study of 6999 patients with GCA and 41994 controls, matched on location, age and gender, was carried out. A competing risk model using aortic aneurysm as the primary outcome and non-aorticaneurysm-related death as the competing risk was used to determine the relative risk (subhazard ratio) between non-GCA and GCA subjects, after adjustment for cardiovascular risk factors.

Results Comparing the GCA cohort with the non-GCA cohort, the adjusted subhazard ratio $(95 \% \mathrm{Cl})$ for aortic aneurysm was 1.92 (1.52 to 2.41). Significant predictors of aortic aneurysm were being an ex-smoker (2.64 (2.03 to 3.43$)$ ) or a current smoker (3.37 (2.61 to 4.37$)$ ) previously taking antihypertensive drugs (1.57 (1.23 to 2.01)) and a history of diabetes (0.32 (0.19 to 0.56$))$ or cardiovascular disease (1.98 (1.50 to 2.63)). In a multivariate model of the GCA cohort, male gender (2.10 (1.38 to 3.19)), ex-smoker (2.20 (1.22 to 3.98)), current smoker (3.79 (2.20 to 6.53)), previous antihypertensive drugs (1.62 (1.00 to 2.61)) and diabetes $(0.19(0.05$ to 0.77$))$ were significant predictors of aortic aneurysm.

Conclusions Patients with GCA have a twofold increased risk of aortic aneurysm, and this should be considered within the range of other risk factors including male gender, age and smoking. A separate screening programme is not indicated. The protective effect of diabetes in the development of aortic aneurysms in patients with GCA is also demonstrated.

\section{INTRODUCTION}

Giant cell arteritis (GCA) is the most common form of vasculitis in the UK, with an incidence of 2.2 cases $/ 10000$ person-years in those over $40{ }^{1}$ Presenting features include headache, scalp tenderness and visual loss. The exact rate of aortic involvement is disputed, but retrospective reviews suggest incidence rates of aortic aneurysm (AA) of 18.7-18.9/1000 person-years. $^{23}$ Screening studies using chest radiography and abdominal ultrasonography, followed by CT where indicated, demonstrate significant aortic dilatation in $22.2 \%$ by 5 years, ${ }^{4}$ while a study of complicated GCA (those with persistent inflammatory markers, arm claudication or suspicion of AA after an average of 37 months of immunosuppressant treatment) found $3 / 15$ patients to have a thoracic AA (TAA), and $12 / 15$ patients thickening of the aortic wall $\geq 4 \mathrm{~mm}$ on MRI. These screening studies did not include controls. A retrospective Canadian population cohort study reported lower rates of aneurysm development at $1 / 1000$ person-years for patients with GCA versus $0.3 / 1000$ person-years in controls, with an adjusted HR (95\% CI) of 3.2 (1.0 to 10.1). ${ }^{5}$ One unmatched population study demonstrated that patients with GCA were 17 times more likely to have a TAA and 2.4 times more likely to have an abdominal AA (AAA) than the normal population ${ }^{6}$; however, the ascertainment of the outcome of AA was different in the two groups in this study. A meta-analysis of patients with GCA estimated that, in cohorts without systematic imaging, 2-8\% developed TAA, ${ }^{7}$ with the authors highlighting the limited data on age-matched controls. Guidelines from the British Society of Rheumatology ${ }^{8}$ and the European League Against Rheumatism ${ }^{9}$ have highlighted the need for further research.

In the general population, the prevalence of AAA has been decreasing, from $5-10 \%$ of men aged $65-79^{10}$ down to $1.7 \%$, secondary to a reduction in smoking. ${ }^{11}$ There is a balance between the $5 \%$ and $6 \%$ mortality with elective repair, ${ }^{12}$ and the $80 \%$ mortality for those with emergency rupture. ${ }^{13}$ AAA screening delivers a relative risk reduction of $30 \%$ in AAA-related deaths within 10 years. ${ }^{14}$ From March 2013, the National Health Service (NHS) AAA Screening Programme has been operational, screening all men at the age of $65 .{ }^{15}$ In the USA, all men aged 65-75 who have ever smoked are offered screening. ${ }^{16-18}$

The General Practice Research Database (GPRD), now renamed the Clinical Practice Research Database (CPRD), comprises general practitioner medical records, covering over 6.25 million patients from 500 practices in the UK. ${ }^{19}$ Stringent data quality standards are applied to anonymised data, ${ }^{19}$ including consultation and prescription records, which are stored using computerised Read codes. The main objective of this study is to evaluate the risk of AA in patients with GCA, the exact rate of which has been disputed, and thereby inform the discussion about the need for specific screening. 


\section{MATERIALS AND METHODS}

\section{Study design using the GPRD}

A 20-year parallel cohort study (containing GCA and non-GCA patients) was observed from 1 January 1991 to 31 December 2010 for the outcome of AA. Ethics approval was given by the GPRD’s Independent Scientific Advisory Committee.

\section{Linked data}

Hospital Episode Statistics (HES) contain details of all admissions to NHS hospitals in England from 1989 onwards, and outpatient attendances from 2003. Patients defined as acceptable by the GPRD are linked to HES. Within HES, diagnoses are classified according to the World Health Organization International Classification of Diseases, edition 10 (ICD-10), and procedures are classified by the Office of Population Censuses and Surveys (OPCS) Classification of Procedures and Interventions codes. The GPRD also offers access to linked Office for National Statistics (ONS) central mortality data by patient ID, which contains the date of death and the cause of death, defined by ICD-10 codes.

\section{Definition of GCA and non-GCA patients}

GCA patients had an incident Read code for GCA between 1 January 1991 and 31 December 2010, and at least two prescriptions for oral corticosteroids, one within 6 months of the diagnosis, with two prescriptions within 6 months, based on validated methodology. ${ }^{1}$ GCA patients were aged 40 or above and had at least 12 months of GPRD-defined up-to-standard data before the date of index diagnosis. Patients were excluded if they had a diagnosis of AA recorded before their GCA.

Non-GCA patients were those without a diagnosis of GCA or polymyalgia ever recorded in the GPRD, who had at least 12 months of up-to-standard follow-up recorded before the date of diagnosis of the matched GCA patient. Non-GCA patients were matched at a $6: 1$ ratio on general practitioner practice, year of birth and gender of the case. Patients were excluded if they had a diagnosis of AA recorded before the GCA diagnosis date of the matched patient.

\section{Outcome measures}

\section{Aortic aneurysm}

Clinical opinion (JCR, AE and RAL) identified GPRD Read codes, ICD-10 and OPCS codes as 'definite' or 'possible' AA, with further categorisation into thoracic, abdominal, thoracoabdominal or unspecified (online supplementary appendix 1).

\section{Death}

The GPRD provides surveillance for vital status of subjects and date but not cause of death. This dataset was linked with ONS mortality data to assess whether the cause of death was related to AAs using ICD-10 codes. Patients with AA listed as a cause of death were classed as having an 'AA event' in the competing risk model and not under 'death'.

\section{Potentially confounding cardiovascular risk factors}

A history of hyperlipidaemia, hypertension or cardiovascular, cerebrovascular or peripheral vascular disease was identified via Read codes. Prior use of lipid-lowering, antihypertensive and diabetic medications was flagged if treatment codes indicated prescriptions for at least $75 \%$ of the year, in any year out of the previous 5 before the diagnosis of GCA or the matched time point in non-GCA patients. Antihypertensive and lipid-lowering medications were considered separate covariates, because of potential protective effects. ${ }^{20} \mathrm{~A}$ history of diabetes was flagged by medical Read codes: a prescription of oral diabetic medications for at least $75 \%$ of the year or two or more prescriptions of injectable insulin or insulin needles in any year out of the previous 5 . Corticosteroid use was not included as a covariate because all patients diagnosed with GCA are routinely treated with glucocorticosteroids. Smoking and alcohol variables had responses of 'current', 'ex' and 'never'. The body mass index (BMI) variable was the closest recorded before the start of the exposed-to-risk period.

\section{Analysis}

GCA patients were 'exposed to risk' of AA from the date of GCA diagnosis to the earliest of the end points: date of death, transfer out (left the study), end of study date, or date of AA diagnosis. Non-GCA patients were exposed to risk from the same date as the corresponding matched GCA patient, with the same end points.

Cumulative incidence function plots stratified by GCA status, gender, smoking status and diabetes were used to describe the probability of AA events over time (see figure 2) and were tested using the log rank test.

Multiple imputation was used to account for the missing values for BMI (28.7\%), smoking (13.6\%) and alcohol $(22.5 \%)$ using imputation by chained equations. ${ }^{21}$ The algorithm generated 10 imputed datasets, which were compared against the original data using distributional plots and tested for similarity using analysis of variance and the $\chi^{2}$ test; the datasets were pooled using Rubin's combination rules for analysis. ${ }^{22}$

A competing risk model ${ }^{23}$ using 'definite AA events in the GPRD' as the outcome $(n=384)$ and death as the competing risk $(n=12011)$ was used to determine the relative risk (subhazard ratio, SHR) between non-GCA and GCA subjects. Univariate models were described and then a full multivariate model with adjustment for cardiovascular risk factors; age and gender were excluded, as the cohorts were matched. Two-way interaction effects between GCA status and the cardiovascular risk factors (and each other) were also investigated. To avoid overfitting the model, each interaction term was individually added to the initial multivariate model; significant terms $(p<0.1)$ were then used to build the final multivariate model.

Sensitivity analyses was performed by replacing the outcome with 'definite AA events in either the GPRD or the HES' and then with 'definite or possible AA event in the GPRD'.

Nested analysis was also performed using any entry of 'definite TAA in the GPRD' as the outcome with all other types of AA outcome removed from the non-GCA and GCA cohorts (along with their corresponding matched subjects). Similarly, the nested analysis was repeated with 'definite AAA in the GPRD' as the outcome. Each cohort was then analysed individually using the same methods, with age and gender now present in the model. All statistical analyses were performed using Stata SE V.12.0.

\section{RESULTS}

\section{Participants}

The flow diagram in figure 1 describes the 6999 patients with GCA and 41994 matched non-GCA subjects in the analysis.

\section{Descriptive statistics}

The GCA cohort had larger proportions of subjects who were ex or current smokers (43.3\% vs $36.8 \%)$, consumed alcohol $(65.0 \%$ vs $63.0 \%)$, had a previous history of hyperlipidaemia $(5.2 \%$ vs $4.3 \%)$, hypertension $(28.7 \%$ vs $26.7 \%)$, diabetes $(9.8 \%$ vs $8.7 \%)$, cardiovascular disease $(9.6 \%$ vs $7.5 \%)$, cerebrovascular disease $(9.0 \%$ vs $6.1 \%)$ or peripheral vascular disease $(2.8 \%$ vs 


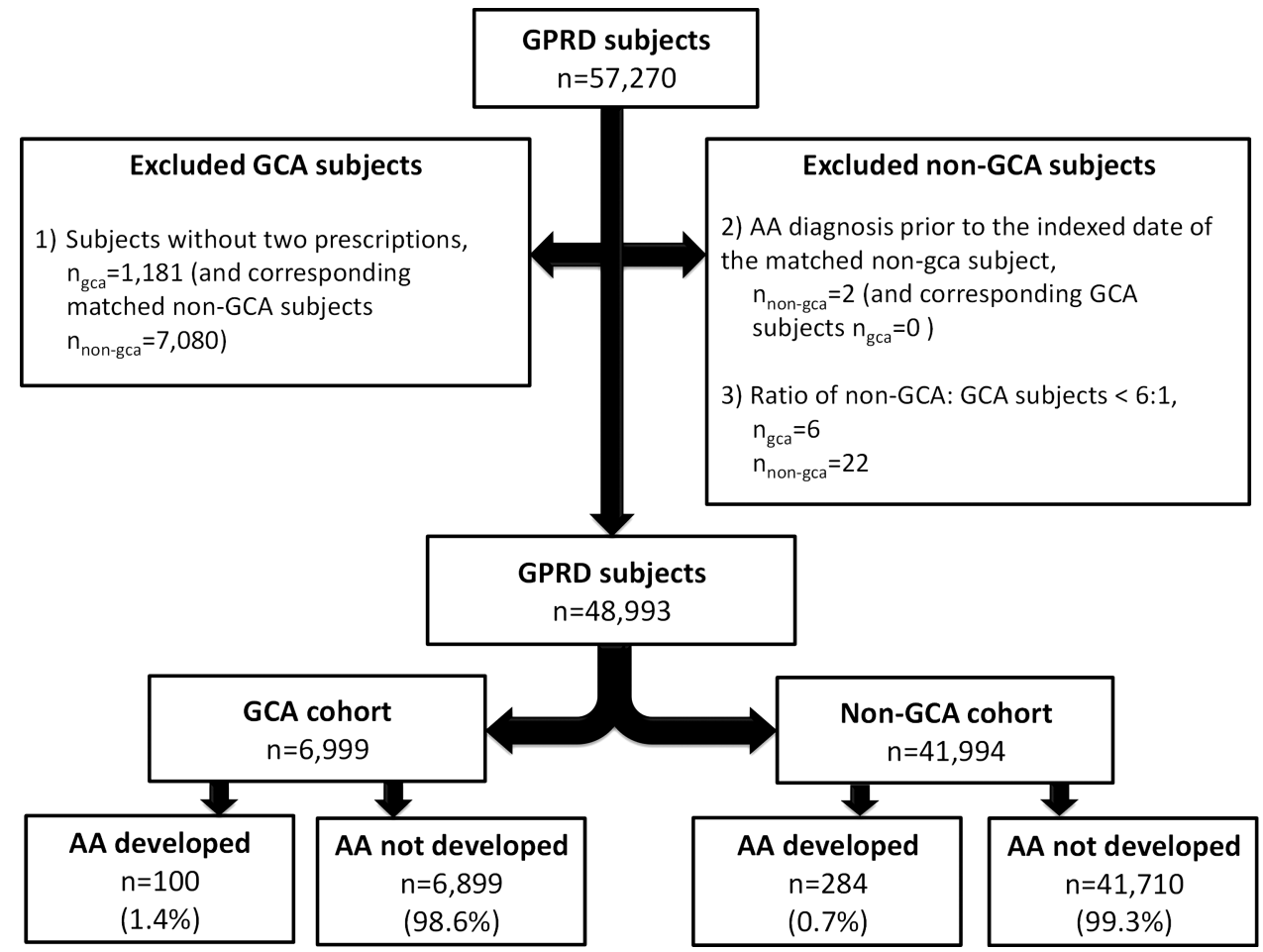

Figure 1 Flow diagram of patients in the study. AA, aortic aneurysm; GCA, giant cell arteritis; GPRD, General Practice Research Database.
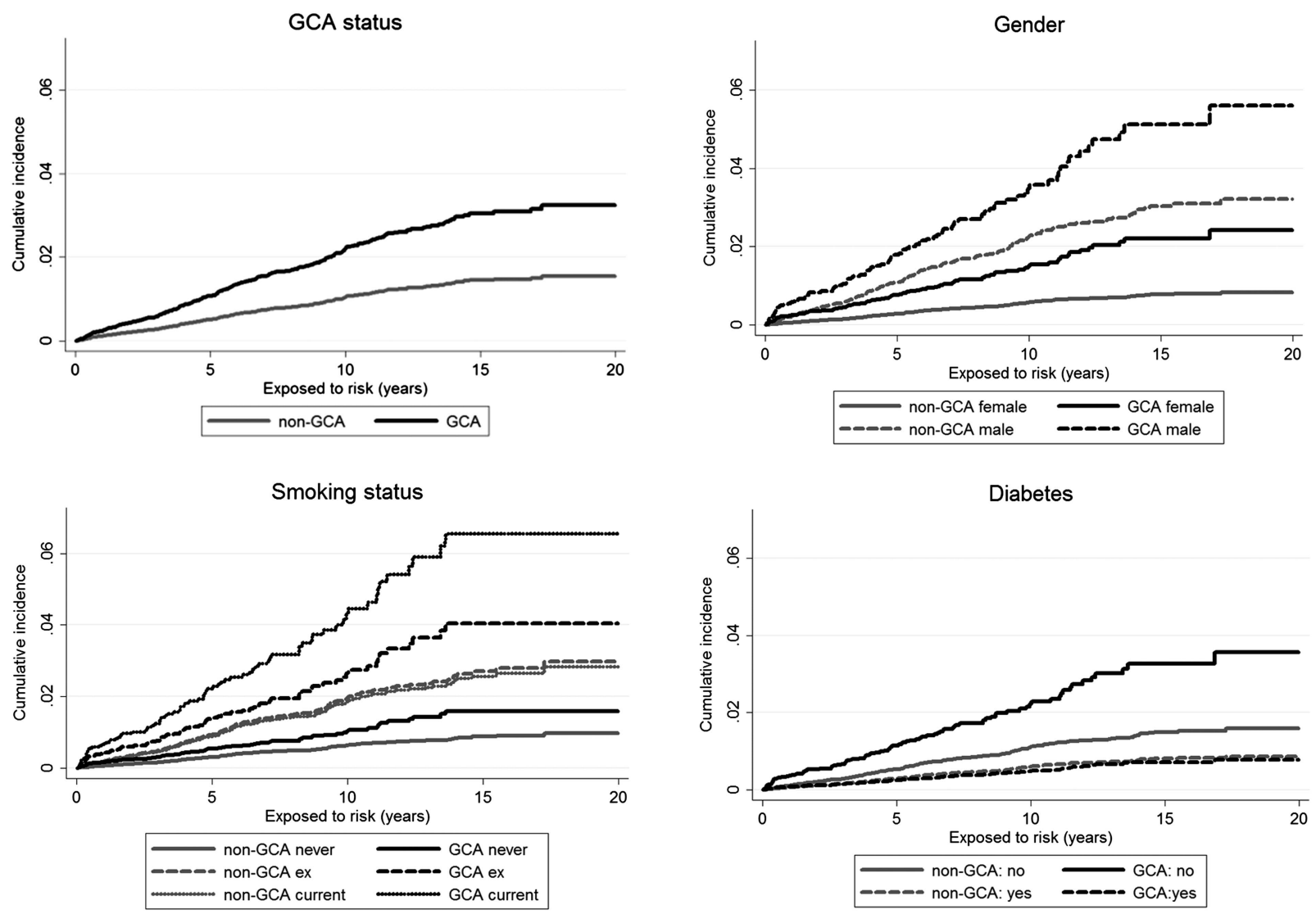

log-rank test for equality of survivor functions: GCA status $p<0.001$; gender (non-GCA) $p<0.001$; gender (GCA) $p<0.001$; smoking (non-GCA status) $p<0.0001$; smoking (GCA status) $p<0.001$; diabetes (non-GCA) $p=0.136$; diabetes (GCA) $p=0.05$.

Figure 2 Cumulative incidence of aortic aneurysm events. GCA, giant cell arteritis. 


\begin{tabular}{|c|c|c|c|}
\hline Factor & $\begin{array}{l}\text { Non-GCA } \\
(n=41994)\end{array}$ & $\begin{array}{l}\text { GCA } \\
(n=6999)\end{array}$ & $\mathrm{p}$ Value \\
\hline Age (years), mean (SD) & $71.9(10.7)$ & $71.9(10.7)$ & 0.978 \\
\hline Gender (male), \% (n) & 28.8 (12 096) & $28.8(2016)$ & 1.000 \\
\hline \multicolumn{4}{|l|}{ BMI $\left(\mathrm{kg} / \mathrm{m}^{2}\right)$} \\
\hline Mean (SD) & $26.6(5.2)$ & $26.6(5.3)$ & 0.736 \\
\hline Missing, \% (n) & $29.3(12325)$ & $24.7(1726)$ & \\
\hline \multicolumn{4}{|l|}{ Smoking, \% (n) } \\
\hline No & $49.0(20573)$ & $46.6(3264)$ & \\
\hline Ex & 23.5 (9859) & $26.8(1878)$ & $<0.001^{* * *}$ \\
\hline Current & $13.3(5601)$ & $16.5(1156)$ & \\
\hline Missing & $14.2(5961)$ & $10.0(701)$ & \\
\hline \multicolumn{4}{|l|}{ Alcohol, \% (n) } \\
\hline No & $13.9(5837)$ & $16.0(1121)$ & \\
\hline Ex & $5.7(2409)$ & $6.5(457)$ & $0.001^{* *}$ \\
\hline Current & $57.3(24045)$ & $58.4(4087)$ & \\
\hline Missing & $23.1(9703)$ & 19.1 (1334) & \\
\hline Prior hyperlipidaemia, \% (n) & $4.3(1785)$ & $5.2(366)$ & $<0.001 * * *$ \\
\hline $\begin{array}{l}\text { Previous prescription of lipid- } \\
\text { lowering medication, \% (n) }\end{array}$ & $14.4(6047)$ & $15.6(1088)$ & $0.012^{*}$ \\
\hline Prior hypertension, \% (n) & 26.7 (11 199) & $28.7(2007)$ & $<0.001^{* * *}$ \\
\hline $\begin{array}{l}\text { Previous prescription of } \\
\text { antihypertensive drugs, \% (n) }\end{array}$ & $36.9(15500)$ & $41.0(2868)$ & $<0.001^{* * *}$ \\
\hline Prior diabetes, \% (n) & $8.7(3657)$ & $9.8(689)$ & $0.002^{* *}$ \\
\hline $\begin{array}{l}\text { Prior cardiovascular disease, } \\
\% \text { (n) }\end{array}$ & $7.5(3135)$ & $9.6(670)$ & $<0.001^{* * *}$ \\
\hline $\begin{array}{l}\text { Prior cerebrovascular disease, } \\
\%(\mathrm{n})\end{array}$ & $6.1(2544)$ & $9.0(631)$ & $<0.001^{* * *}$ \\
\hline $\begin{array}{l}\text { Prior peripheral vascular } \\
\text { disease, \% (n) }\end{array}$ & $1.7(715)$ & $2.8(193)$ & $<0.001^{* * *}$ \\
\hline $\begin{array}{l}\text { Aortic aneurysm during study, } \\
\% \text { (n) }\end{array}$ & $0.7(284)$ & $1.4(100)$ & $<0.001 * * *$ \\
\hline Death during study, \% (n) & 23.8 (9989) & $28.9(2022)$ & $<0.001^{* * *}$ \\
\hline $\begin{array}{l}\text { Exposed to risk (years), } \\
\text { median (IQR) }\end{array}$ & $4.5(1.9-8.0)$ & $4.1(1.6-7.7)$ & $<0.001^{* * *}$ \\
\hline
\end{tabular}

$1.7 \%)$ and took lipid-lowering medication (15.6\% vs $14.4 \%)$ or antihypertensive drugs (41.0\% vs $36.9 \%$ ), as shown in table 1 .

\section{Death}

Within the ONS dataset, 25552 subjects had matched IDs with the GPRD ( $n=48$ 933). Of these, 18090 did not have a death recorded in either, 5005 contained death values in both with causes listed by ICD-10 codes, 1434 had death recorded in the ONS but not the GPRD, and 1023 had death recorded in the GPRD but not the ONS (sensitivity 0.78 , specificity 0.95 ). The sensitivity and specificity reflect the very low levels of misclassification of death status in the GPRD compared with HES data. AA was not listed as the cause of death in any of the 5005 matched subjects.

\section{Risk of AA in patients with GCA}

The risk of AA in subjects with GCA is $1.4 \%$ compared with $0.7 \%$ in non-GCA subjects, giving a risk ratio of 2.0 . The corresponding rates were $2.8 / 1000$ person-years and $1.2 / 1000$ person-years, giving a rate ratio of 2.3 . These figures were supported by the competing risk analysis using death as the competing risk.
'Definite AAA GPRD Read codes' were used as the outcome for the primary analysis. The univariate competing risk model compared the GCA cohort with the non-GCA cohort (reference group) to give an unadjusted SHR (95\% CI) of 2.11 (1.68 to $2.65)$, shown in table 2 . In the multivariate model, with adjustment for BMI, smoking, alcohol, hyperlipidaemia, lipidlowering medication, hypertension, antihypertensive drugs, diabetes, cardiovascular disease, cerebrovascular disease and peripheral vascular disease, the SHR $(95 \% \mathrm{CI})$ was 1.92 (1.52 to 2.41); significant predictors were ex-smoker (2.64 (2.03 to $3.43)$ ), current smoker (3.37 (2.61 to 4.37$)$ ), previous prescription of antihypertensive drugs (1.57 (1.23 to 2.01)) and history of diabetes $(0.32$ (0.19 to 0.56$))$ or cardiovascular disease $(1.98$ (1.50 to 2.63)). No significant two-way interaction effects were observed between GCA status and the covariates $(\mathrm{p}<0.1$ for all interactions). ${ }^{i}$ On testing Schoenfeld residuals, the proportionality assumption was not violated.

The first sensitivity analysis used 'definite AA events in either GPRD or the HES database' as the outcome. A total of 20807 subjects were identified in both databases, with 20492 being AA free in both databases, 115 having AA in both databases, 72 having AA in GPRD but not HES, and 128 having AA in HES and not GPRD (sensitivity 0.473 , specificity 0.996 ). The SHR $(95 \% \mathrm{CI})$ in this multivariate model was 1.68 (1.36 to 2.06). In addition, when 'definite or possible AA events' was used in the GPRD as the outcome, the SHR (95\% CI) was 1.94 (1.55 to 2.43) (table 2). These sensitivity analyses support the primary analysis.

When the Read code included sufficient description, the sub-type of each AA was identified. In all, 38.8\% (149/384) of the total number of AA cases were classified as thoracic or abdominal and the remainder were unspecified. In the nested univariate analysis, the SHR (95\% CI) using AAA and TAA as the outcome was 1.63 (1.04 to 2.53) and 6.58 (2.80 to 15.50), respectively. On multivariate analysis using AAA as the outcome, the SHR (95\% CI) was 1.51 (0.97 to 2.37); there were insufficient TAA events.

\section{Predictors of AA}

On multivariate modelling, gender, smoking and diabetes were significant predictors in the GCA cohort and non-GCA cohorts, with cardiovascular disease and cerebrovascular diseases also predicting AA in the non-GCA group (table 3). No significant two-way interaction effects were observed between covariates $\left(\mathrm{p}<0.1\right.$ for all interactions) ${ }^{\mathrm{ii}}$ (table 3$)$. Interactions of the following covariate pairs could not be statistically
assessed because of a low frequency cell count $(<13)$ when
cross-tabulated with AA: GCA status and statins, GCA status and
cardiovascular disease, GCA status and peripheral vascular disease,
smoking status and peripheral vascular disease, hyperlipidaemia and
peripheral vascular disease, cardiovascular disease and hypertension.
ii Interactions of the following covariate pairs could not be statistically
assessed because of a low frequency cell count $(<5)$ when
cross-tabulated with AA: for the GCA cohort-gender and diabetes,
gender and peripheral vascular disease, smoking status and statins,
smoking status and diabetes, smoking status and diabetes, smoking status
and cerebrovascular disease, smoking status and peripheral vascular
disease, hyperlipidaemia and peripheral vascular disease, statins and
antihypertensive drugs, statins and cardiovascular disease,
antihypertensive drugs and diabetes, antihypertensive drugs and
peripheral vascular disease, diabetes and peripheral vascular disease,
cardiovascular disease and peripheral vascular disease, cerebrovascular
disease and peripheral vascular disease; for the non-GCA cohort-
gender and antihypertensive drugs, hyperlipidaemia and peripheral
vascular disease, diabetes and cerebrovascular disease. 
Table 2 Subhazard ratios $(95 \% \mathrm{CI})$ of non-GCA/GCA groups using the competing risk model (imputed data)

\begin{tabular}{|c|c|c|c|c|}
\hline Analysis & Risk of AA & Risk ratio & $\begin{array}{l}\text { Univariate model } \\
\text { (SHR }(95 \% \mathrm{CI}))\end{array}$ & $\begin{array}{l}\text { Multivariate modelt } \\
\text { (SHR }(95 \% \mathrm{CI}) \text { ) }\end{array}$ \\
\hline \multicolumn{5}{|c|}{ Primary analysis } \\
\hline Non-GCA & $0.68 \%(284 / 41994)$ & - & Reference & Reference \\
\hline GCA & $1.43 \%(100 / 6999)$ & 2.1 & $2.11(1.68 \text { to } 2.65)^{* * *}$ & $1.92(1.52 \text { to } 2.41)^{* * *}$ \\
\hline \multicolumn{5}{|c|}{ Sensitivity analysis 1} \\
\hline Non-GCA & $0.93 \%(391 / 41994)$ & - & Reference & Reference \\
\hline GCA & $1.73 \%(121 / 6999)$ & 1.9 & $1.86(1.51 \text { to } 2.28)^{* * *}$ & $1.68(1.36 \text { to } 2.06)^{* * *}$ \\
\hline \multicolumn{5}{|c|}{ Sensitivity analysis 2} \\
\hline Non-GCA & 0.70\% (292/41 994) & - & Reference & Reference \\
\hline GCA & $1.49 \%(104 / 6999)$ & 2.1 & $2.14(1.71 \text { to } 2.67)^{* * *}$ & $1.94(1.55 \text { to } 2.43)^{* * *}$ \\
\hline
\end{tabular}

Cumulative incidence plots also demonstrate differences in the risk of AA when stratified by GCA status, gender, smoking and diabetes (figure 2).

\section{DISCUSSION}

This study demonstrates a twofold increased relative risk of AA in patients with GCA, compared with age-, gender- and location-matched controls from the general population of the UK, independent of cardiovascular risk factors. Independent predictors for AA in both GCA and non-GCA cohorts include the male gender and smoking, which is consistent with previous studies. ${ }^{4}{ }^{17} 24-26$ A previous history of diabetes is shown to be protective against developing AA; this has been noted in the general population, ${ }^{18}{ }^{27-29}$ but is the first demonstration in patients with GCA. The pathophysiology of this protective effect may be related to advanced glycation inducing collagen cross-linking and strengthening of the aortic media. ${ }^{30}$ Prior use of antihypertensive medications is also associated with subsequent AA in this study, and may be acting as a surrogate for hypertension, as previous authors have found hypertension to be predictive. ${ }^{3}$ Patients with GCA are usually considered to have survival rates equivalent to the age-matched population ${ }^{31}$; however, evidence has been mixed. ${ }^{32}$ In our cohort, we found a higher mortality in the GCA cohort; this may be because prior cardiovascular and cerebrovascular disease were more commonly seen in GCA patients.

Because AAs are usually asymptomatic, the main limitation of using the GPRD to define the outcome of AA is that patients are most likely to have been identified incidentally rather than through a systematic screening programme, ${ }^{4}$ and this may be a reason for the low incidence of $\mathrm{AA}$ seen. The rate of $\mathrm{AA}$ in this study is $2.8 / 1000$ person-years in the GCA cohort and 1.2/1000 person-years in the non-GCA cohort, giving a rate ratio of 2.3 ; this is lower than the rate of AA and/or dissection of 18.9/1000 person-years ${ }^{3}$ and $18.7 / 1000$ person-years $^{2}$ in two retrospective cohorts. These studies did not account for death as a competing

Table 3 Subhazard ratios $(95 \% \mathrm{Cl})$ using the competing risk model for each non-GCA/GCA cohort (imputed data)

\begin{tabular}{|c|c|c|c|c|}
\hline \multirow[b]{2}{*}{ Factor } & \multicolumn{2}{|l|}{ Non-GCA ( $n=41$ 994) } & \multicolumn{2}{|l|}{ GCA $(n=6999)$} \\
\hline & Univariate & Multivariate & Univariate & Multivariate \\
\hline Age (years) & $1.03(1.02 \text { to } 1.04)^{* * *}$ & 1.00 (0.99 to 1.02 ) & $0.99(0.98$ to 1.00$)+$ & 0.97 (0.94 to 1.00$)$ \\
\hline BMI $\left(\mathrm{kg} / \mathrm{m}^{2}\right)$ & 0.99 (0.97 to 1.02 ) & 1.00 (0.97 to 1.03$)$ & 0.99 (0.95 to 1.03$)$ & 1.00 (0.96 to 1.04$)$ \\
\hline Male gender & $3.95(3.11 \text { to } 5.01)^{* * *}$ & $3.49(2.70 \text { to } 4.52)^{* * *}$ & $2.36(1.59 \text { to } 3.49)^{* \star *}$ & $2.10(1.38 \text { to } 3.19)^{* *}$ \\
\hline Ex-smoker & $3.02(2.24 \text { to } 4.08)^{* * *}$ & $2.08(1.52 \text { to } 2.85)^{* * *}$ & $2.58(1.49 \text { to } 4.47)^{\star *}$ & $2.20(1.22 \text { to } 3.98)^{* *}$ \\
\hline Current smoker & $3.02(2.21 \text { to } 4.13)^{* * *}$ & $3.00(2.17 \text { to } 4.14)^{* * *}$ & $4.24(2.50 \text { to } 7.16)^{\star * *}$ & $3.79(2.20 \text { to } 6.53)^{* * *}$ \\
\hline Previous alcohol & $1.66(0.90$ to 3.03$)+$ & 1.16 (0.63 to 2.14 ) & 0.68 (0.20 to 2.34 ) & 0.62 (0.19 to 1.99$)$ \\
\hline Current alcohol & 1.28 (0.85 to 1.92 ) & 0.94 (0.62 to 1.43 ) & 1.26 (0.72 to 2.21$)$ & 0.91 (0.52 to 1.60$)$ \\
\hline Prior HLD & $1.88(1.14 \text { to } 3.11)^{*}$ & 1.37 (0.80 to 2.34 ) & 1.04 (0.38 to 2.82 ) & 1.19 (0.40 to 3.53$)$ \\
\hline Prior HLD treatment & $1.97(1.44 \text { to } 2.71)^{* * *}$ & 1.21 (0.83 to 1.76 ) & 0.77 (0.37 to 1.60$)$ & 0.69 (0.31 to 1.50$)$ \\
\hline Prior HT & 1.16 (0.89 to 1.51$)$ & 0.92 (0.68 to 1.24 ) & 0.91 (0.57 to 1.43 ) & 0.93 (0.55 to 1.58$)$ \\
\hline Prior $\mathrm{HT}$ treatment & $1.72(1.36 \text { to } 2.16)^{* * *}$ & $1.42(1.06 \text { to } 1.89)^{*}$ & 1.23 (0.83 to 1.83 ) & $1.62(1.00 \text { to } 2.61)^{*}$ \\
\hline Prior DM & $0.54(0.30 \text { to } 0.97)^{*}$ & $0.32(0.18 \text { to } 0.58)^{* * *}$ & $0.22(0.05 \text { to } 0.88)^{*}$ & $0.19(0.05 \text { to } 0.77)^{*}$ \\
\hline Prior CVD & $2.83(2.10 \text { to } 3.81)^{* * *}$ & $1.65(1.20 \text { to } 2.29)^{* *}$ & 1.38 (0.77 to 2.47 ) & 1.28 (0.72 to 2.29$)$ \\
\hline Prior CBVD & $1.36(0.88 \text { to } 2.09)_{+}$ & 0.88 (0.56 to 1.38 ) & 0.82 (0.38 to 1.77 ) & 0.79 (0.36 to 1.73$)$ \\
\hline Prior PVD & $2.93(1.68 \text { to } 5.13)^{* * *}$ & $1.84(1.04 \text { to } 3.25)^{*}$ & 0.70 (0.17 to 2.86 ) & 0.68 (0.17 to 2.72 ) \\
\hline
\end{tabular}


risk, and are unmatched, and therefore it is possible that they may have overestimated the risk of AA. This study did not, however, select patients on biopsy or American College of Rheumatology classification criteria, and therefore may include patients with milder disease. ${ }^{2} 3$ From imaging studies, patients with GCA develop aortic structural damage within 5 years. ${ }^{33}$ The median exposure time is 4.3 years, potentially leading to an underestimation of the incidence. A screening programme for patients with GCA has not been recommended, but there is awareness that AAs are more common in this group, ${ }^{34}$ and this may lead to increased investigations in GCA patients, potentially introducing bias. There is also a risk that delayed ascertainment of the diagnosis of AA may result in inappropriate inclusion of patients. Although two-thirds of AAs in this study were unspecified as to their type, with multivariate analysis therefore not possible, on univariate analysis the SHR $(95 \% \mathrm{CI})$ for TAA was 6.58 (2.80 to 15.50), and for AAA 1.63 (1.04 to 2.53), a striking difference, which supports the findings of previous authors. ${ }^{2}{ }^{3}{ }^{6}$ Glucocorticoids are the standard treatment for $\mathrm{GCA}^{8}$; it was not therefore possible to separate the effect of treatment and disease in this analysis, and their use was not included as a separate covariate, although their use may theoretically play a role in aneurysm development.

A randomised controlled trial to demonstrate benefit of screening in patients with GCA would be the gold standard methodology of answering this research question, but may not be feasible, because of the rarity of events and relatively low overall incidence of GCA. Even in non-GCA patients, over 125000 men were enrolled in four randomised controlled trials of screening, to demonstrate a significant reduction in AAA-related mortality. ${ }^{14}$ There are also aspects of the natural history of AAs that are unknown in patients with GCA, and this may affect the risk-benefit analysis of a screening programmefor example, the rate of progression of aneurysms or the outcome after emergency or elective repair. This study demonstrates a twofold increased risk of AA in patients with GCA, although the limitations mean that quantifying the absolute risk in general, and specifically for sub-types of aneurysm, is not possible at present. Known risk factors for AA in the general population, including male gender, age and hypertension, are also important. This study cannot support a specific screening programme, but GCA should be considered as a risk factor for AA within the range of other known risk factors.

Contributors All authors contributed to the study proposal, design of the analysis and interpretation of the findings. JCR and AK produced the analysis plan. JM was responsible for data extraction. $\mathrm{AK}$ and $\mathrm{AH}$ undertook the analysis with input from JCR and RAL. All authors, internal and external, had full access to the data (including statistical reports and tables) in the table and can take responsibility for the integrity of the data and the accuracy of the data analysis. JCR wrote the first draft of the paper which was revised by all authors. JCR and AK will act as guarantors.

Funding Grant from the NIHR Research for Patient Benefit (RfPB) Programme (PB-PG-0610-22408). Funders reviewed the study design protocol but had no role in collection, analysis, interpretation of data, writing of the report, or decision to submit the article for publication.

Competing interests List of competing interests are as follows. (1) JCR, JM, $A H_{\text {, }}$ $N A, B D, W H, D C, A E$ and RAL received a grant from the NIHR Research for Patient Benefit (RfPB) Programme to fund this study. JCR, AK, JM, AH, NA, BD, WH, DC, AE and RAL had no support from any commercial companies for the submitted work. (2) $A K, J M, A H, W H, D C$ and AE have no relationships with companies which might have an interest in the submitted work in the previous 3 years. JCR has received a travel bursary from Chugai Pharma. NA has the following relationships; consultancies for Flexion (PharmaNet), Lily, Merck, Q-Med, Roche and Smith \& Nephew; grants/ grants pending with Novartis, Pfizer, Schering-Plough and Servier and received payment for lectures from Amgen, GSK, NiCox and Smith \& Nephew. BD has the following relationships; board membership Roche-advisor in GCA; consultancy for
Mundi Pharma on PMR. RAL has the following relationships; consultancies for Nordic Pharma, Chemocentryx, Human Genome Science; grants/grants pending with Nordic Pharma. (3) JCR, AK, JM, AH, NA, BD, WH, DC, AE, RAL their spouses, partners, or children have no financial relationships that may be relevant to the submitted work; and (4) JCR, AK, JM, NA, WH, DC, AE, RAL have no non-financial interests that may be relevant to the submitted work. $A H$ and $B D$ are members of the group that produced the British Society of Rheumatology/British Health Professionals in Rheumatology 2010 guidelines for the management of giant cell arteritis.

Ethics approval General Practice Research Database's Independent Scientific Advisory Committee (ISAC).

Provenance and peer review Not commissioned; externally peer reviewed.

\section{REFERENCES}

1 Smeeth L, Cook C, Hall AJ. Incidence of diagnosed polymyalgia rheumatica and temporal arteritis in the United Kingdom, 1990-2001. Ann Rheum Dis 2006;65:1093-8

2 Nuenninghoff DM, Hunder GG, Christianson TJ, et al. Incidence and predictors of large-artery complication (aortic aneurysm, aortic dissection, and/or large-artery stenosis) in patients with giant cell arteritis: a population-based study over 50 years. Arthritis Rheum 2003;48:3522-31.

3 Gonzalez-Gay MA, Garcia-Porrua C, Pineiro A, et al. Aortic aneurysm and dissection in patients with biopsy-proven giant cell arteritis from northwestern Spain: a population-based study. Medicine (Baltimore) 2004;83:335-41.

4 Garcia-Martinez A, Hernandez-Rodriguez J, Arguis P, et al. Development of aortic aneurysm/dilatation during the followup of patients with giant cell arteritis: a cross-sectional screening of fifty-four prospectively followed patients. Arthritis Rheum 2008;59:422-30.

5 Ray JG, Mamdani MM, Geerts WH. Giant cell arteritis and cardiovascular disease in older adults. Heart 2005;91:324-8.

6 Evans JM, O'Fallon WM, Hunder GG. Increased incidence of aortic aneurysm and dissection in giant cell (temporal) arteritis. A population-based study. Ann Intern Med 1995:122:502-7.

7 Mackie SL, Hensor EM, Morgan AW, et al. Should I send my patient with previous giant cell arteritis for imaging of the thoracic aorta? A systematic literature review and meta-analysis. Ann Rheum Dis. Published Online First 22 Dec 2012.

8 Dasgupta B, Borg FA, Hassan N, et al. BSR and BHPR guidelines for the management of giant cell arteritis. Rheumatology (Oxford) 2010;49:1594-7.

9 Mukhtyar C, Guillevin L, Cid MC, et al. EULAR recommendations for the management of large vessel vasculitis. Ann Rheum Dis 2009:68:318-23.

10 Vardulaki KA, Prevost TC, Walker NM, et al. Incidence among men of asymptomatic abdominal aortic aneurysms: estimates from 500 screen detected cases. J Med Screen 1999;6:50-4.

11 Svensjo S, Bjorck M, Gurtelschmid M, et al. Low prevalence of abdominal aortic aneurysm among 65-year-old Swedish men indicates a change in the epidemiology of the disease. Circulation 2011;124:1118-23.

12 The UK Small Aneurysms Trial Participants. Mortality results for randomised controlled trial of early elective surgery or ultrasonographic surveillance for small abdominal aortic aneurysms. Lancet 1998;352:1649-55.

13 Basnyat PS, Biffin A, Moseley L, et al. Vascular surgical society of great britain and ireland: deaths from ruptured abdominal aortic aneurysm in wales. $\mathrm{Br}$ J Surg 1999:86:693.

14 Cosford PA, Leng GC. Screening for abdominal aortic aneurysm. Cochrane Database Syst Rev 2007;CD002945.

15 NHS Abdominal Aortic Aneurysm Screening Programme. http://aaa.screening.nhs.uk/

16 U.S. Preventive Services Task Force. Screening for abdominal aortic aneurysm: recommendation statement. Ann Intern Med 2005;142:198-202.

17 Sode BF, Nordestgaard BG, Gronbaek M, et al. Tobacco smoking and aortic aneurysm: two population-based studies. Int J Cardiol 2012;167:2271-7.

18 Lederle FA, Johnson GR, Wilson SE, et al. The aneurysm detection and management study screening program: validation cohort and final results. Aneurysm Detection and Management Veterans Affairs Cooperative Study Investigators. Arch Intern Med 2000;160:1425-30.

19 Walley T, Mantgani A. The UK General Practice Research Database. Lancet 1997;350:1097-9.

20 Dunne JA, Bailey MA, Griffin KJ, et al. Statins: the holy grail of Abdominal Aortic Aneurysm (AAA) growth attenuation? A systematic review of the literature. Curr Vasc Pharmacol 2012 [Epub ahead of print].

21 Royston P. Multiple imputation of missing values: update of ice. The Stata Journal 2005;5:527-36

22 Barnard J, Meng XL. Applications of multiple imputation in medical studies: from AIDS to NHANES. Stat Methods Med Res 1999;8:17-36.

23 Fine J, Gray R. A proportional hazards model for the subdistribution of a competing risk. J Am Stat Assoc 1999;94:496-509.

24 Machado EB, Gabriel SE, Beard CM, et al. A population-based case-control study of temporal arteritis: evidence for an association between temporal arteritis and degenerative vascular disease? Int J Epidemiol 1989;18:836-41. 
25 Duhaut P, Pinede L, Demolombe-Rague S, et al. Giant cell arteritis and cardiovascular risk factors: a multicenter, prospective case-control study. Groupe de Recherche sur I'Arterite a Cellules Geantes. Arthritis Rheum 1998;41:1960-5.

26 Larsson K, Mellstrom D, Nordborg E, et al. Early menopause, low body mass index and smoking are independent risk factors for developing giant cell arteritis. Ann Rheum Dis 2006;65:529-32.

27 Lederle FA, Larson JC, Margolis KL, et al. Abdominal aortic aneurysm events in the women's health initiative: cohort study. BMJ 2008;337:a1724.

28 Rodin MB, Daviglus ML, Wong GC, et al. Middle age cardiovascular risk factors and abdominal aortic aneurysm in older age. Hypertension 2003;42:61-8.

29 Iribarren C, Darbinian JA, Go AS, et al. Traditional and novel risk factors for clinically diagnosed abdominal aortic aneurysm: the Kaiser multiphasic health checkup cohort study. Ann Epidemiol 2007:17:669-78.
30 Golledge J, Karan M, Moran CS, et al. Reduced expansion rate of abdominal aortic aneurysms in patients with diabetes may be related to aberrant monocyte-matrix interactions. Eur Heart J 2008;29:665-72.

31 Phillip R, Luqmani R. Mortality in systemic vasculitis: a systematic review. Clin Exp Rheumatol 2008;26:S94-104

32 Crow RW, Katz BJ, Warner JE, et al. Giant cell arteritis and mortality. J Gerontol A Biol Sci Med Sci 2009;64:365-9.

33 Garcia-Martinez A, Arguis P, Preito-Gonzalez S, et al. Prospective evaluation of aortic structural damage (aneurysm/dilatation) using a predefined screening protocol in biopsy-proven giant-cell arteritis patients with extended follow-up. Arthritis Rheum 2011;63:\$593-4.

34 Mukhtyar C, Guillevin L, Cid MC, et al. EULAR recommendations for the management of primary small and medium vessel vasculitis. Ann Rheum Dis 2009:68:310-17. 